\title{
THE BEHAVIORAL ECONOMICS OF SMOKING
}

\author{
Warren K. Bickel \\ Gregory J. Madden
}

Working Paper 6444 


\title{
NBER WORKING PAPER SERIES
}

\section{THE BEHAVIORAL ECONOMICS OF SMOKING}

\author{
Warren K. Bickel \\ Gregory J. Madden
}

Working Paper 6444

http://www.nber.org/papers/w6444

\section{NATIONAL BUREAU OF ECONOMIC RESEARCH \\ 1050 Massachusetts Avenue \\ Cambridge, MA 02138 \\ March 1998}

\begin{abstract}
The research was supported by National Institute on Drug Abuse grant DA06526 and T32 DA07242. We wish to thank Gary Badger who assisted in data analysis, Rob McIntyre from the Vermont Department of Health who provided data concerning demographics of US smokers and Brandi Smith and Lisa Marsch, who provided useful comments on an earlier version of this paper. This paper was prepared for the National Bureau of Economic Research conference on the Economic Analysis of Substance Use and Abuse, Cambridge, MA, March 27-28, 1997. Any opinions expressed are those of the authors and not those of the National Bureau of Economic Research.
\end{abstract}

(C) 1998 by Warren K. Bickel and Gregory J. Madden. All rights reserved. Short sections of text, not to exceed two paragraphs, may be quoted without explicit permission provided that full credit, including (C) notice, is given to the source. 
The Behavioral Economics of Smoking Warren K. Bickel and Gregory J. Madden

NBER Working Paper No. 6444

March 1998

\section{ABSTRACT}

Evidence that economic principles may be employed to predict the rates at which cigarettes are consumed is presented from several laboratory experiments. In these experiments, cigarettedeprived smokers were required to make a effortful response to earn cigarette puffs. Changing the number of responses required per puff is conceptualized as a price manipulation. Our experiments demonstrate that these price increases decrease cigarette consumption and that price elasticity of demand increases with increases in price. When data from 74 different smokers, participating in 17 different experiments, in our laboratory were analyzed, five demographic variables were related to rates of earning and smoking cigarettes in the lab: 1) males smoked more than females; 2) lesseducated individuals tended to smoke more than better-educated smokers; 3) higher rates of smoking were observed in individuals with high Fagerström Tolerance Questionnaire scores; 4) light drinkers were found to smoke more than heavy drinkers; and 5) unemployed subjects smoked more than employed individuals. Demographic effects on price elasticity did not accord as well with econometric data. Finally, we discuss the ability of behavioral-economic laboratory experiments to model cigarette smoking in the natural economy, and the validity of using these laboratory results as a means of assessing the likely effects of public-policy initiatives. The results from one such experiment are presented that suggest the economic concept of inferior goods may be informative in understanding nicotine-replacement products and the likely effects of differential pricing of cigarettes and these replacement products.

Warren K. Bickel

Department of Psychiatry

University of Vermont

Burlington, VT 05401-1419
Gregory J. Madden

Department of Psychiatry

University of Vermont

Burlington, VT 05401-1419 
...an adequate science of behavior should supply a satisfactory account of individual behavior which is responsible for the data of economics...

-B.F. Skinner (1953), Science and Human Behavior (p. 400)

This quote addresses a point central to our discussion; namely, the relation between the behavior of individuals and groups. Traditionally, the behavior of individuals and groups have been the domain of different professions. Individual behavior was the domain of psychology, while group behavior, in terms of the allocation of scarce resources, was the domain of economics. However, some psychologists in the late 1970's began to observe similarities between the phenomena that they studied and economic concepts and principles (e.g., Allison, 1979; Green \& Rachlin, 1975; Hursh, 1980; Lea, 1978). This precipitated the development of behavioral economics. In the late 1980's, behavioral economics began to be consistently applied to the study of drug abuse and dependence and today is an active area of investigation (e.g., Bickel, DeGrandpre, Higgins, \& Hughes, 1990; Bickel, DeGrandpre, Hughes, \& Higgins, 1991; Carroll, Lac, \& Nygaard, 1989; Hursh, 1991).

A critical part of research efforts in the behavioral economics of drug abuse should be to test the limits of the applicability of economic theories and research findings (cf. Sechrest \& Bootzin, 1996). Understanding these limits will indicate the relation between individual and group drug use and the extent to which one can inform the other. The results of this examination will ultimately influence the relation between the economics and behavioral economics of drug abuse and indicate the extent to which behavioral economic research findings may inform policy.

This examination should attempt to answer two research questions: First, are economic concepts and principles applicable to the drug taking of individuals and second, do behavioral-economic data reflect empirical results from econometric studies of drug use? 
The first of these two questions is a necessary predecessor to the second. If economic concepts and principles are found to be applicable to the drug use of individuals, then the generality of economic concepts is established. Moreover, this generality would permit the study of broad variations in controlling variables in the laboratory. For example, prices in the behavioral economic laboratory can be varied over a greater range than typically observed in the natural economy. Information from such experiments would inform economists about the possible consequences for drug use of larger magnitude price changes.

The second question asks whether the empirical findings noted in the econometrics of drug abuse are observed in the behavioral economics laboratory. For example, if econometric studies find that consumption of a particular drug of abuse differs as a function of gender, then the results from similar conditions across several behavioral economic studies could be examined for those gender differences. Of course, this would require the development of a substantial data base from the behavioral economics laboratory, composed of a sample of research subjects that are representative of the populations of interest. Such comparative analyses, to what ever extent possible, would begin to establish the generality and limitations of data collected in the behavioral economic laboratory. Such information would lead to circumscribed and clearly defined justifications for generalizing to policy from behavioral economic laboratory data.

Perhaps, the best substance for examining the similarity of the behavioral economics of individual consumption and the economics of aggregate consumption is tobacco smoking. Two reasons support the value of smoking for this comparison. First, tobacco cigarettes are commercially available. Thus, substantial amounts of information about prices and consumption of tobacco cigarettes are available for economic analyses without the difficulty typical with illegal drugs. Second, the behavioral economics of cigarette smoking is among the most developed research areas in the behavioral economics of drug abuse (e.g., Bickel et al., 1990, 1991; Bickel, Hughes, DeGrandpre, Higgins, \& 
Rizzuto, 1992), thereby permitting detailed comparisons with econometric studies. Of course, tobacco smoking, as the single greatest preventable cause of death, is an important public health problem to study.

The purpose of this paper is to attempt to answer three questions-two of them posed earlier. First, are economic concepts and principles applicable to the smoking behavior of individuals? Second, do behavioral-economic data reflect empirical results from econometric studies of cigarette smoking? Third, can the behavioral economics laboratory evaluate or suggest smoking policies? Before addressing these three issues, we will first describe our experimental paradigm.

\section{Overview of the Experimental Paradiem and Analysis}

Typically the cigarette smokers that participate in our research are recruited from newspaper advertisements. To participate, each subject must be age 18 or older, smoke $\geq$ 20 cigarettes ( $>.5 \mathrm{mg}$ nicotine yield) per day, and have a carbon monoxide level of greater than $20 \mathrm{ppm}$. Subjects undergo medical and psychiatric screening prior to participation. Individuals with active alcohol/drug abuse, medical, or psychiatric problems that would interfere with participation are excluded. Subjects are instructed not to eat solid foods for 4 hours, not to drink caffeinated or other acidic beverages (e.g., coffee, tea, soda, juice) for 6 hours, or alcohol for 18 hours prior to the start of the session, or use illicit drugs for the duration of the study.

The general arrangement that has been employed to examine the behavioral economics of cigarette smoking is as follows. Cigarette smokers come to the laboratory 2 to 5 times per week, depending upon the study, to participate in 3-hour sessions (see Bickel et al., 1991, for more details). Subjects are required to refrain from smoking for 5 to 6 hours prior to each session as indicated by carbon monoxide $(\mathrm{CO})$ breath readings (a reliable indicator of recent smoking). After meeting the $\mathrm{CO}$ requirement, the subject is provided with one puff on a cigarette to equate time from last cigarette smoking across subjects. The session begins thirty minutes later. 
In most of our experiments, we do not employ a medium of exchange (e.g., money). Thus, subjects must make a specified number of responses in order to smoke. Responses are defined a complete pull and reset of a brass plunger (Gerbrands No. G6310) located on a console in front of the subject. At the beginning of each session, the subject is informed of the number of responses required for access to a cigarette and the number of puffs on that cigarette that will be permitted upon each completion of the response requirement. In most cases, completion of a response requirement results in the administration of 2 to 4 puffs on a cigarette. During the sessions, the subject sits alone in a small room with the response apparatus, a radio, and the local newspaper. When the response requirement is completed, the subject is provided with the specified number of puffs on a cigarette. Puffs are inhaled using a controlled-puffing procedure (Griffiths, Henningfield, \& Bigelow, 1982; Zacny et al., 1987). Specifically, subjects inhale through a puff-volume sensor that provides visual and auditory feedback designed to ensure that subjects inhale $70 \mathrm{cc}(+/-5 \mathrm{cc})$ per puff throughout the experiment. Various modifications of these basic procedures will be discussed below as they become relevant. Note that unless otherwise specified, consumption refers to the number of puffs on a cigarette that are smoked and drug-seeking refers to number of responses on the plunger.

\section{Are Economic Concepts Relevant to the Cigarette Smoking of Individuals?}

Fundamental to economics is the concept of demand and the demand law. First, demand is the quantity of a good or reinforcer that an individual will purchase or consume at the prevailing price (Pearce, 1986; Samuelson \& Nordhaus, 1985). Second, the law of demand specifies that the amount of a good that will be bought will decrease with increases in price, all other things being equal (Pearce, 1986). If the demand law is applicable to cigarette smokers, then consumption should decrease as price increases.

The law of demand is illustrated by a recent study conducted in our laboratory (Bickel, DeGrandpre, Higgins, Hughes, \& Badger, 1995). Five cigarette-deprived smokers could obtain 2 puffs on a cigarette for completing 100 responses. In a later 
session, the requirement was increased to 400 responses, a 4-fold increase in price. Figure 1 illustrates that this increase in price decreased each subject's consumption in accordance with the demand law. Note that the results are not peculiar to these subjects nor to this preparation. Indeed, the effects of increasing price via response requirements has been demonstrated with a wide variety of drug and other reinforcers in several species (Griffiths, Bigelow, \& Henningfield, 1980).

One way to quantify the effects of price is with a measure of demand referred to as elasticity. Elasticity is defined as responsiveness of consumption to changes in price (Samuelson \& Nordhaus, 1985). The quantitative measure of elasticity is the elasticity coefficient. The elasticity co-efficient (also referred to as arc elasticity) is defined as the percentage change in the quantity purchased divided by the percentage change in price. By virtue of being expressed as the percentage change in demand, this measure is independent of the units of the commodity and the price. Elasticity co-efficients result in values that are either elastic or inelastic. Elastic demand refers to proportionally large decreases in consumption as price increases, while inelastic demand refers to proportionally small decreases in consumption as price increases (Hursh \& Bauman, 1987). Elastic and inelastic demand correspond with elasticity co-efficients with absolute values of greater than and less than 1 , respectively.

Table 1 displays the elasticity co-efficients for the data presented in Figure 1. The across-subject mean elasticity is.- .46 , with elasticity co-efficients ranging from -.3 to -.76 . These co-efficients indicate that demand is inelastic and relatively insensitive to price. Econometric assessments of cigarette price elasticity of demand typically range from $(-.16$ to -.80; Andrews \& Franke, 1991). Although price elasticities of our laboratory smokers fell within this range of elasticities estimated by econometricians, it should be noted that the 
latter elasticity estimates take into consideration price effects on both cigarette consumption and the decision to smoke (i.e., initiation of smoking in nonsmokers). Because the latter is not assessed in our laboratory studies, our elasticity estimates over the price range shown in Figure 1 would probably be higher than econometric estimates of price elasticities based on cigarette consumption alone.

Although a single price-elasticity value is provided by examining the effects of a single price increase, elasticity may not be constant across a broad range of prices. Examining a broad range of prices is a strength of laboratory behavioral-economic research. As mentioned earlier, the price range that can be imposed can far exceed the range of prices observed in the natural economy of cigarette smokers. For example, in some of our studies prices can range from 1 to 2,600 or more which spans more than three orders of magnitude. By assessing a variety of prices, demand can be displayed graphically as a demand curve where the amount of goods consumed is plotted as a function of that good's price (Pearce, 1986).

Figure 2 displays demand curves from the same 5 subjects whose data were presented in Figure 1. The demand curves illustrate the relation between cigarette consumption and the unit price at which cigarette puffs could be purchased. Unit price is defined as a cost-benefit ratio: the number of responses made in order to obtain each cigarette puff. The data in Figure 2 are plotted according to mathematical convention where the independent variable is plotted on the horizontal axis and the quantity consumed is plotted on the vertical axis. Thus, these axes are inverted relative to economic convention. The line of best fit is derived by an equation developed by Hursh, Raslear, Bauman, and Black (1989) to model consumption (see Equation 1, below). Consumption generally decreases as price increases consistent with the law of demand. Importantly, these data 
indicate that elasticity (slope) changes throughout the demand curve with the absolute value of elasticity increasing as price increases.

Given that elasticity is changing continuously as price changes, point elasticities were calculated for each price. Point elasticity is the slope of the line tangent to a point on the demand curve (see Equation 3 below). These coefficients (displayed in Table 2) show that the absolute value of elasticity tends to increase as price increases. At low prices, elasticity values are near zero and positive in value in a few cases. As price increases, elasticity becomes more negative until at the higher prices they are elastic (i.e., $>1$ in absolute value). A commodity that is inelastic at the lower range of prices and becomes more elastic at higher prices is considered to exhibit mixed elasticity (Hursh \& Bauman, 1987). Moreover, consumption can be said to positively decelerate as a function of price increases when plotted in log coordinates. Mean point-price elasticities for each subject are displayed in Table 2 . The across-subject mean elasticity was -.46 , with mean elasticity coefficients ranging from -.45 to -.83 . These data suggest that elasticity is non-linear and that the shape of the demand function may prove useful in making predictions about the effects of price changes on cigarette demand. We will address this later in greater detail.

Of course, these results may be peculiar to environments without a medium of exchange. To address this, DeGrandpre \& Bickel (1995) conducted a study where a medium of exchange was employed. Subjects were presented with the opportunity to earn money by completing a response requirement. The money earned could then be spent on cigarettes. To obtain the opportunity to smoke also required that subjects complete a 
response requirement in order to spend their money on cigarette puffs. By doing so the cost of cigarettes was broadened to include both monetary cost and the effort (e.g., travel time to the store) required to obtain cigarettes. In each session, subjects made a number of response requirements to obtain $\$ 0.25$ and completed a range of response requirements to spend their earnings on cigarettes. Money could not be taken home and was relevant only in the context of the session.

Figure 3 shows the demand curves obtained when puffs purchased per session are plotted as a function of the unit price of cigarette puffs (here the response and monetary cost of cigarettes are included in calculations of unit price). The demand curves shown in this figure are generally similar in shape to those seen in Figure 2; that is, consumption is a positively decelerated function of price increases. Also, note the between-subject differences in the sensitivity of consumption to price. The latter differences are evident when point elasticities at each unit price are examined (Table 3). As price increases, demand for cigarettes becomes progressively more elastic. The across-subject mean elasticity was -1.58 and mean elasticities ranged from -.66 to -3.27 . Note that the elasticities are higher than in the preceding study. However, so is the range of prices examined. In this study, prices ranged from 400 to 4500 , while in the prior study prices ranged from 12 to 1600 . Given that elasticity is price-dependent as shown in both of these data sets, these differences in elasticity are to be expected when different prices are examined.

Although the demand curves examined thus far are somewhat variable across subjects, they may all be described as positively decelerating when plotted on log 
coordinates, and all show mixed elasticity. Thus, the important characteristics of laboratory smokers' demand curves are observed whether or not a medium of exchange is employed in manipulations of price.

One important question about these data are the generality of the findings; that is, are these findings restricted to the laboratory where sessions are three hours long and puffs are delivered instead of cigarettes or packs. The usefulness of behavioral economic data would be enhanced to the extent that these results are related to broader aspects of economic behavior. To address this, we will first consider whether similar results would be obtained if longer duration studies were conducted.

In 1966, Jack Findley reported a study that he conducted where a cigarette smoker lived 24 hours a day in an experimental space. In order to obtain cigarettes, the subject had to complete a response requirement. The response requirement was varied across days, not within. Thus, Findley employed procedures nearly identical to those used in our experiments, but expanded the duration of the session to 24 hours and used whole cigarettes instead of puffs on a cigarette.

Data from Findley's (1966) experiment are presented in Figure 4. When plotted in double log coordinates, cigarette smoking decreased as a positively decelerating function of cigarette price. As the response requirement increased $(25,50,100,200,300$, and 500), elasticity increased from values near zero, indicating inelastic demand, to elastic demand at the highest price (See Table 4). Overall mean elasticity was -.41 . Thus, these data indicate that demand curves observed in our laboratory sessions appear representative of consumption across full days and when whole cigarettes are purchased. However, Findley's data were also collected under laboratory conditions. 
To further assess the generality of the shape of demand curves observed in our laboratory, we reanalyzed the aggregate US cigarette consumption data that were reported by Lewit (1989). In that paper, Lewit reported per capita consumption and annual retail price of cigarettes in the US as a function of calendar years. From Lewit's Figures 2 and 5 we produced a demand curve by plotting per capita consumption of cigarettes as a function of price on double-logarithmic coordinates. Although other data provided in Lewit's figures were adjusted for inflation, it is unclear from Lewit's Figure 2 whether annual cigarette prices were adjusted for inflation. Figure 5 illustrates that although cigarette prices did not span a large range, the shape of the demand curve is similar to those obtained in our laboratory setting. Point elasticities are provided in Table 5 at each of the prices shown in the figure. Again, elasticity increases across this price range and overall elasticity for these data are -.29 .

The shape of the cigarette demand curve may have substantial generality across other drugs as well. For example, consider the data presented in Figure 6. In the figure, demand curves were reanalyzed from several drug self-administration studies that employed a variety of drugs and species including monkeys and rats (Bickel et al., 1990). Regardless of whether cocaine, PCP or pentobarbital was being self-administered, the shape of the demand curve generally conformed to that characterizing demand for cigarettes. 
Summary. Together, the data examined thus far suggest that basic principles and concepts of economics apply to the behavioral economics laboratory where the behavior of cigarette smokers are studied. The data demonstrate that elasticity changes continuously throughout the demand curve and that mixed elasticity is often observed. The shape of this function is observed when both response requirements are manipulated and when medium of exchange procedures are employed. Moreover, the shape of the demand function appears to have generality to 24-hour sessions, when full cigarettes are earned, to aggregate US consumption, and to other drugs of dependence when studied in laboratory settings. Together these data, answer in the affirmative our question regarding the relevance of basic economic concepts to the cigarette smoking of individuals.

\section{Does Behavioral Economic Data Reflect Empirical Results From Econometric Studies of}

\section{Cigarette Smoking?}

To assess whether cigarette smoking in the behavioral economics laboratory may serve as an adequate model of smoking in broader economic contexts, we sought to compare data collected in our laboratory over the past eight years with some major findings in the smoking literature. First, we compared price elasticity of demand for cigarettes in the behavioral economics laboratory with those commonly reported by econometricians and those derived from per capita US smoking. Next, we assessed whether demographic characteristics known to correlate with price elasticity values and rates of cigarette consumption could also significantly account for observed variance in elasticity and consumption of cigarettes in our laboratory. To the extent that laboratory and nonlaboratory demand for cigarettes are comparably affected by smokers' demographic characteristics, behavioral economic data may be useful in predicting the effects of cigarette price increases outside the range investigated in econometric studies.

Cigarette-smoking data were collected from subjects who participated in one of 17 different experiments. Because each of these experiments was designed to investigate a different aspect of demand for cigarettes, we used only those subjects whose data had been 
collected under conditions most commonly employed in our studies. That is, data were included in the analysis if cigarette-deprived subjects pulled a response plunger at different response requirements to self-administer cigarette puffs in 3-hour sessions. We included in the analysis only those subjects' data that included at-least four different unit prices. A minimum of four unit prices are required to fit the demand curve (see Equation 1 below). Because we were interested in the relation between demographic characteristics of individual smokers and their cigarette intake, we included only one demand curve for each individual subject. For subjects who had completed multiple experiments, data from the experiment corresponding to the highest $\mathrm{R}^{2}$ was used. These inclusion and exclusion criteria yielded 74 separate demand curves, each derived from individual-subject data.

The functional relation between cigarette-puff consumption (C) and unit price (P) was modeled by using the following equation (Hursh et al., 1989):

$$
C=L_{p}^{b} e^{-4 p}
$$

or restated in logarithmic coordinates:

$$
\log \mathrm{C}=\log \mathrm{L}+\mathrm{b}(\log \mathrm{P})-\mathrm{aP}
$$

where $\underline{L}$ and $\underline{b}$ are related to initial consumption and slope of the demand curve, respectively, and $\underline{a}$ is a measure of acceleration in slope. Parameter estimates were obtained through linear regression techniques. Demand curves fit through individual-subject data accounted for a mean of $92 \%$ of the variance $(\mathrm{SD}=9.4 \%)$.

Table 6 shows demographic characteristics of the final group of subjects employed in the present analyses. Subjects were about evenly split between males and females, were primarily white, and were on-average middle-aged, high-school educated and unemployed. Subjects tended to smoke more than a pack of cigarettes and drink about three cups of coffee per day. Most subjects drank alcohol, with about one-third of all subjects reporting regular drinking (i.e., $\geq 2$ drinking episodes per week) and over half of the subjects reporting consuming more than one drink at each episode. Fagerstrom Tolerance 
Questionnaire (FTQ) scores suggested our average subject was nicotine dependent, while the average Beck's Depression Inventory score was in the nondepressed range.

Although our sample of subjects well represented the range of some demographic characteristics (e.g., gender), others were constrained relative to the demographics of US smokers. For example, our subjects smoked an average of 26 cigarettes a day with a one standard-deviation range of 18-34 cigarettes. During the period 1990-1991 (the most recent period for which demographic data were available), the average US smoker consumed approximately 19 cigarettes per day and approximately $35 \%$ of all smokers consumed fewer than 15 cigarettes per day (Giovino et al., 1994). Younger smokers and heavy alcohol users are not represented in our sample because persons under 18-years old or suspected of having a drinking problem were excluded from participating in the experiments. Unemployed or under-employed smokers tend to be overrepresented in our sample given that most subjects participated during business hours for modest compensation. Further, the ethnic mix of the US population was not well represented in our sample of smokers, although it was representative of the geographic location in which the experiments were conducted.

Figure 7 shows the predicted number of cigarette puffs consumed per session as a function of eight different unit prices $(10,25,50,100,200,400,800,1600)$; note the double-logarithmic coordinates. The eight unit prices shown were selected because they correspond to the range typically examined in our laboratory studies and are approximately equidistant when plotted on logarithmic coordinates. Because subjects were generally not given the opportunity to earn cigarette puffs at each of these unit prices, the number of puffs consumed per session at each unit price is estimated from average parameter values of 
individual subjects' demand curves. As Figure 7 illustrates, logarithmic demand for cigarettes was a positively decelerating function of logarithmic price increases.

Price elasticity of demand values were calculated at each of the eight different unit prices from parameters of individual subjects' demand curves using the following equation:

$$
E=b-a P
$$

The mean and standard error of these estimated values are shown in Table 7. As defined by the model of cigarette consumption employed (Equation 1), price elasticity values are a decreasing linear function of price.

Clearly, the range of price elasticity of demand values presented in Table 7 is wider than is typically reported in econometric studies investigating the effects of price fluctuations on demand for cigarettes (e.g., Andrews \& Franke, 1991; Townsend, 1987). In the latter, average price elasticity values typically range between -0.4 (Lewit \& Coate, 1982) and -0.8 (Andrews \& Franke, 1991). Only a portion of our empirically derived demand curve (between unit prices 200 and 400) possessed elasticities approximating the range reported by econometricians. At unit prices lower than 200 , demand was more inelastic and at prices higher than 400 , demand shifted from inelastic to elastic.

Thus, mean price elasticities derived from individual smokers' laboratory demand curves are in-part consistent with values reported in econometric studies of cigarette demand. The price elasticity differences that were observed (below and above unit prices 200 and 400 , respectively) may be a function of the limited range of cigarette prices typically examined in econometric investigations of cigarette smoking - limited, that is 
when compared with the 160-fold range of unit prices represented in Table 7. As shown in Table 5, price elasticity values of US demand for cigarettes range between -0.14 and -0.47 when prices are varied across an approximately two-fold range. While this range is still constrained relative to the mean elasticities reported in Table 7, the shape of the US demand curve shown in Figure 5 suggests that further price increases would produce greater shifts toward elastic demand.

In summary, mean elasticities generated in the behavioral economics laboratory are partially consistent with elasticities reported in econometric studies of cigarette smoking. Differences are hypothesized to be the result of the broader range of unit prices examined in our lab than cigarette prices in econometric investigations. Our laboratory demand curve closely resembles US demand for cigarettes when prices are varied across a two-fold range.

Demographics of Smoking. The demographics of our sample of smokers (Table 6) provide the opportunity to examine if the number of cigarette puffs consumed per session and price elasticities of demand across a range of unit prices are affected by characteristics of smokers participating in our laboratory studies. If some of these characteristics are found to explain the variability in smoking rates and sensitivity to price within the lab, then these relations between demographics and smoking can be compared with demographic effects observed outside the lab. That is, characteristics of real-world smokers that are known to affect per capita cigarette consumption or price elasticity of demand could be compared with those demographics found to affect smoking in our laboratory. Consistent demographic effects across laboratory and nonlaboratory settings would further support the use of the present methods as a model of population-level cigarette smoking and, in addition, would suggest that laboratory results obtained from subjects with specific demographic characteristics can be used to predict the effects of price changes on the behavior of demographic subpopulations of cigarette smokers. 
Two cautions are warranted, however, before endeavoring to make these comparisons. First, as noted above, some demographic subpopulations of smokers were not well represented in our sample. For some demographics, ethical or practical constraints barred us from gathering a more representative sample of smokers. For example, teenage and alcoholic smokers were excluded from participating in our experiments. Although no systematic income data were collected from our sample of smokers, we believe that smokers in higher socioeconomic (SES) classes were not well represented because most experimental sessions were conducted during business hours, subjects were required to participate for several weeks in each experiment, and we suspect the monetary compensation employed was insufficient to attract higher SES smokers. Second, our sample of smokers is far smaller than those employed in econometric studies. Thus, a failure to observe consistent demographic effects between behavioral economic and econometric studies indicates either that our sample was unrepresentative of the population of smokers, that our sample size was insufficient to detect significant differences, or that behavioral economic laboratory data cannot be used to predict effects of cigarette price changes on demand of demographic subpopulations of smokers.

Numerous studies, some of them econometric, have outlined the demographics of cigarette smoking. For example, male smokers typically smoke more cigarettes per day than female smokers (Giovino et al., 1994) and male demand for cigarettes tends to be more price elastic than is female demand (Chaloupka, 1990; Chaloupka \& Wechsler, 1994; Mullahy, 1985; although see Townsend, Roderick, \& Cooper, 1994). Age is positively related to the number of cigarettes consumed per day (Giovino et al., 1994) and some econometric studies have found a negative relation between age and price elasticity (e.g., Lewit \& Coate, 1982); although the latter effect appears primarily due to a decrease in the number of young people who begin smoking after cigarette price increases (Lewit \& Coate, 1982; Lewit, Coate, \& Grossman, 1981). Additionally, unemployed and lower SES persons are more likely to be smokers (Hay \& Foster, 1984), although most econometric 
studies have reported greater price elasticity in lower socioeconomic status smokers than in wealthier populations of smokers (Atkinson, Gomulka, \& Stern, 1984; Fry \& Pashardes, 1988; Townsend, 1987; Townsend et al., 1994).

Other demographic variables represented in our sample of laboratory smokers are known to be correlated with smoking rates, topography, or success in attempts to quit smoking, but their relation to price elasticity, to our knowledge, have not been investigated. The Fagerstrom Tolerance Questionnaire (FTQ; Fagerstrom \& Schneider, 1989) is an eight-item paper and pencil measure of nicotine dependence. Higher FTQ scores are correlated with less success in attempts to quit smoking (Pinto, Abrams, Monti, \& Jacobus, 1987). Education level is both negatively correlated with US per capita smoking rates (Pierce et al., 1989) and the number of cigarettes consumed per day (Giovino et al., 1994). Alcohol consumption has also been found to modestly but significantly correlate with daily cigarette intake (Craig \& Van Natta, 1977).

To compare demographic effects between our sample of laboratory smokers and smokers outside the lab, we began by confining our comparison to the unit price range possessing price elasticities comparable to mean elasticities reported in econometric studies. Thus, our initial comparison was confined to unit prices 200 and 400 (mean arc elasticity = $-0.44, \mathrm{SE}=0.40$ ). The demographic characteristics listed in Table 6 were considered as potential predictors in stepwise regression analyses for (a) arc elasticity across unit prices 200 and 400, (b) cigarette intake per session at unit price 200, and (c) intake at unit price 400. Demographic variables were chosen for inclusion in the model if the F-to-enter was significant at $\mathrm{p} \leq .10$.

Arc Elasticity. Table 8 shows the two demographic variables that were significant in predicting arc elasticity across unit prices 200 and 400: FTQ score and years of education. The upper panel in Figure 8 shows the relation between FTQ scores and predicted arc elasticities, while the lower panel illustrates the relation between education level and predicted arc elasticities. FTQ scores of 4, 7, and 10 served as low, middle, and 
high values, and 9, 12.5, and 16 years of education were used to represent the range of education levels (each of these values fell within the range observed in our sample of smokers). At high FTQ scores, demand for cigarettes was more inelastic than at low scores, consistent with FTQ as a measure of nicotine dependence. Similarly, cigarette demand is more inelastic in low educated smokers than in highly educated smokers. Thus, the most inelastic demand in this unit price range is predicted for poorly educated smokers with high FTQ scores.

To our knowledge neither FTQ score nor education level has been studied in econometric studies of price elasticity of demand for cigarettes. FTQ scores are predictive of success in smoking cessation treatment studies (e.g., Pinto et al., 1987) and may, therefore, be predictive of price elasticity of demand for cigarettes (although the latter has not been empirically determined). Consistent with this argument, smokers with higher FTQ scores tend to more efficiently compensate when changed to low nicotine-yield cigarettes (Fagerstrom \& Bates, 1981), a change which may be conceptualized as a price increase (i.e., lower nicotine delivery for the same amount of money spent on cigarettes; see DeGrandpre, Bickel, Hughes, \& Higgins, 1992) which induces compensatory behavior representative of inelastic demand. Further, high FTQ scores would appear to predict inelastic demand for cigarettes in nicotine-dependent smokers who are more likely to experience withdrawal symptoms relative to nondependent smokers, when nicotine intake is decreased in the face of cigarette price increases. The latter, however, is not empirically supported as Hughes and Hatsukami (1986) found no significant relation between FTQ score and nicotine withdrawal severity. Thus, the relation between FTQ 
score and price elasticity requires prospective empirical study to determine if the present finding accurately characterizes the behavior of smokers outside the laboratory.

The relation between education level and price elasticity of demand shown in Figure 8 is qualitatively consistent with the observation that smoking prevalence rates have declined more in smokers with a high-school education or higher (Escobedo \& Peddicord, 1996); although the latter findings may be more a function of public education efforts concerning the health risks of smoking than they are indicative of price elasticity differences across education levels. Indeed, Chaloupka (1991) reported that education was negatively related to price elasticity of demand, a result opposite that obtained in our sample of laboratory smokers. The inconsistency between our findings and those reported by Chaloupka may be due to our sample of smokers inadequately representing the larger population of cigarette smokers. In particular, the range of SES levels of US smokers does not appear to have been well represented in our sample of laboratory smokers, and SES is a variable known to correlate with education level (e.g., Neisser et al., 1996). Although SES data were not systematically collected in our sample, we believe lower SES smokers were disproportionately represented. Most of our subjects (55.4\%) were unemployed and 45\% of our employed subjects were employed part-time only. Further, subjects in our experiments agreed to participate in exchange for $\$ 35$ (US) per day; a rate likely to attract predominantly lower SES smokers. Thus, in our relatively homogenous group of lower SES subjects, education was positively related to price elasticity. Whether the same education-consumption relation would be observed in low SES smokers in the natural economy remains an empirical question.

Noticeably absent from the variables significantly predicting variance in elasticity between unit prices 200 and 400 were gender and age, both of which have been reported to affect price elasticity of demand for cigarettes (e.g., Townsend, 1994). T-tests of elasticity at unit prices 200 and 400 (calculated from Equation 3) revealed no significant effect of gender at either unit price. Because male and female smokers were about equally 
represented in our sample, the failure of this demographic to account for variability in elasticity in our smokers is surprising. The insignificant effect of age on price elasticity, however, may be due to the lack of younger smokers in our sample. Townsend (1994) found no systematic effect of age on elasticity above age 24 . In our sample of smokers, $\mathbf{7 7 \%}$ were 25 years or older. Thus, age may have failed to significantly account for variance in elasticity simply because of our lack of sufficient variability in smokers' ages.

Cigarette Consumption at Unit Prices 200 and 400 . Five demographic variables significantly accounted for variance in the number of cigarettes puffs consumed per session at unit price 200 and four of these variables were significant at unit price 400 . Table 9 shows the order in which variables were selected in stepwise regression, parameter coefficients, and percent variance accounted for by each variable in the final equations. In Figure 9, predicted smoking rates at unit prices 200 and 400 are shown as a function of gender (upper-left panel), education level (middle-left panel), FTQ score (middle-right panel), alcohol consumption per episode (lower-left panel), and employment status (lowerright panel). In each figure, cigarette consumption was estimated by multiplying each significant demographic variable's parameter coefficient by a high and low value of the demographic at unit prices 200 and 400 . High and low parameter values fell within the range of observed values of each demographic variable. The mean of the remaining demographics in the regression equations were multiplied by their parameter coefficients.

Several findings corresponded with demographic trends observed in US smokers. First, consistent with data reported by Giovino et al. (1994), male laboratory smokers consumed more cigarette puffs per session than females. Thus, although laboratory 
elasticities were nonsignificantly affected by gender across the unit price 200 to 400 range, cigarette consumption was sensitive to this variable. Second, consistent with data summarized by Pierce et al. (1989), education was negatively related to cigarette intake. Thus, our high-educated subjects smoked fewer cigarette puffs per session and showed greater price elasticity of demand. Third, higher rates of intake were predicted by the stepwise equation for subjects with high FTQ scores; an unsurprising result given that selfreported daily smoking intake is an item on the FTQ. The lower-left panel of Figure 9 illustrates an unanticipated finding: subjects who reported drinking fewer than 2 alcoholic beverages per drinking episode were predicted to smoke more cigarette puffs per session than heavier drinkers. Finally, unemployed subjects were predicted to be heavier smokers than employed subjects at unit price 200; employment did not account for significant variance in consumption at unit price 400 (and thus is not shown in Figure 9).

In summary, education level and FTQ score accounted for significant variance in arc elasticity across the unit price 200 to 400 range. To our knowledge, these demographic variables have not been studied as predictive of price elasticity of demand in econometric studies of cigarette smoking. Age and gender, two variables found to affect populationlevel price elasticities, did not significantly account for variance in arc elasticity across this range of unit prices. Whether these inconsistencies are representative of a quantitative difference between laboratory and nonlaboratory demand when cigarette prices are manipulated, or are due to a lack of variability in the demographics of our sample of laboratory smokers (age) or statistical power (age \& gender) remains unclear. Regardless of their origin, these inconsistencies fail to support using the results of the present experiments as predictors of specific age and gender subpopulations of smokers' reactions to cigarette price changes.

With the exception of alcohol use per drinking episode, smokers' demographic characteristics affected the amount smoked at unit prices 200 and 400 in a direction consistent with demographic effects observed at the population level of smokers. These 
consistencies suggest that the present data set could be used to predict whether demographic effects observed within this confined range of unit prices (viewed as representative of cigarette prices outside the lab) would be maintained if cigarette prices are increased or decreased to levels outside this range. Because the effects of alcohol consumption variables on smoking rates did not correspond with reported correlations between alcohol use and cigarette consumption rates outside the lab, these variables were not subjected to further analyses.

Demographic Effects on Cigarette Consumption Across a 160-Fold Range of Unit Prices. T-tests were used to compare the predicted number of cigarette puffs consumed per session at each of eight different units price across two levels of the demographics shown in Table 6. Thus, continuous demographic variables (e.g., age) were dichotomized at a level that resulted in two approximately equally sized samples. The same eight unit prices used to estimate demand in Figure 7 were employed for this analysis. Cigarette consumption per session was again estimated from mean demand curve parameters using Equation 1.

The upper-left panel of Figure 10 shows the effects of gender on predicted cigarette consumption across this range of unit prices. At unit prices up to 200 , males were predicted to smoke significantly more puffs per session than were female smokers. However, as unit prices increased above 200 , gender differences failed to reach significant levels. These data may suggest that if cigarette prices were increased above current levels, male and female smokers would tend to smoke about the same number of cigarettes per day. These data also suggest an elasticity difference between male and female smokers across the lower range of unit prices; however, this difference was not detected in our stepwise regression analysis of arc elasticity across unit prices 200 and 400 . The suggested trend toward greater price elasticity in male smokers is consistent with some (e.g., Chaloupka, 1990; Chaloupka \& Wechsler, 1994; Mullahy, 1985) and inconsistent with other (Townsend et al., 1994) econometric findings. 
The upper-right panel of Figure 10 shows a similar effect profile of age on cigarette intake across the eight unit prices. For purposes of these analyses, smokers over and under age 30 were treated as separate groups. Older smokers smoked significantly more cigarette puffs per session than younger smokers at unit prices less than 200. At higher unit prices, intake differences observed across the different age groups failed to achieve significance; suggesting again that if cigarette prices were increased, demographic differences in smoking rates would wane.

The lower-left panel of Figure 10 illustrates that significant cigarette intake differences were observed at all eight unit prices across two levels of education. Education was dichotomized into two groups of subjects ( $<$ and $\geq a$ high-school education). Predicted consumption levels were significantly higher for subjects with less than a high school education. The lower-right panel of Figure 10 shows that FTQ scores were significant or approached significance only at unit prices higher than 200 .

Summary and Conclusions. So, does the behavioral economic data reflect empirical results of econometric studies of cigarette smoking? Using behavioral economic laboratory smoking data to predict population-level changes in price elasticity of demand was supported by two pieces of evidence. First, the range of price elasticities commonly reported in econometric studies fell within the range of elasticities derived from demand across the 160 -fold range of unit prices examined. Second, price elasticities indicative of more extremely inelastic demand than is typically reported in econometric studies were consistent with price elasticities derived from US per capita smoking rates across a twofold range of cigarette prices. Laboratory data indicative of extreme elasticity were hypothesized to be a function of the higher prices employed in our studies than have been implemented in the US tobacco market. 
Our retrospective stepwise regression analysis of demographic variables accounting for variance in price elasticity, however, revealed significant effects of FTQ score and education level when elasticities were examined in a unit price range considered representative of prices typically examined in econometric studies. Gender and age, two variables found to affect price elasticity in econometric studies of cigarette smoking, did not significantly account for elasticity variance in our sample of laboratory smokers. Thus, little evidence was gathered to support using behavioral economic laboratory smoking data to predict how price changes might affect price elasticity in specific demographic subpopulations of smokers. However, the possibility that the latter conclusion represents a Type-II error should not be overlooked given the small samples size employed (relative to econometric studies) and the fact that our sample of smokers were not representative of many of the demographic characteristics of cigarette smokers.

Finally, demographic characteristics known to affect the number of cigarettes consumed per day were, in general, predictive of cigarette smoking rates in the behavioral economics lab. Thus, men tended to smoke more per session than women and participants over age 30 smoked significantly more than their younger counterparts across the lower range of unit prices examined. In the upper range of unit prices, these demographic differences disappeared as smoking rates converged around minimal consumption levels. More educated subjects smoked significantly less per session throughout the unit price range.

The notable exception to the consistencies between demographic variables affecting laboratory and nonlaboratory smoking rates was alcohol use, which is positively related to daily smoking rates in smokers outside the lab, but was negatively related to puffs per session in the lab at nearly all but the highest unit price. There are at least two possible explanations for this discrepancy. First, heavy drinkers were excluded from participating in our studies. Perhaps if this population of smokers been included, laboratory smoking would have been positively related to alcohol consumption. Second, there is evidence to 
suggest that cigarettes and alcohol are complementary goods (e.g., Zacny, 1990). In a complementary relation, increasing the availability of one good (e.g., soup) increases the consumption of that good and its complement (soup crackers). If a complementary relation exists between cigarettes and alcohol, then our heavier drinkers may have been lighter smokers in the lab because alcohol was unavailable during the sessions and negative BAL readings were required for participation.

Can The Behavioral Economics Laboratory Be Used To Develop And Evaluate Economic Policy Recommendations For Cigarette Smoking?

The preceding section suggests that when we aggregate our data, we obtain results that are generally consistent with smoking in the natural economy. When disaggregated into demographic subgroups, our data are in some cases consistent with the economics of smoking in the natural economy and in some cases not. This suggests that while our laboratory model may not accurately predict the reactivity of certain subgroups of smokers to cigarette price changes, our model nonetheless seems to conform to aggregate smoking in the natural economy. As such, the relation between laboratory studies and aggregate smoking may permit us to explore experimentally the consequences of policies already imposed and to examine other economic phenomena that may inform smoking policy, although the results of these experiments may not reflect how certain subgroups may respond. To this end, we will summarize the results of an experiment with policy-making implications (DeGrandpre, Bickel, Rizvi, \& Hughes, 1993). This experiment provides an empirical demonstration of the economic concepts of normal and inferior goods, and here we will discuss the implications of these findings for smoking policy.

Normal and inferior goods are concepts that may have important implications for the relative pricing of nicotine replacement products and tobacco cigarettes. Normal goods are defined as commodities that are increasingly consumed as income increases. In contrast, consumption of inferior goods decreases when income increases. For example, at 
low incomes, more hamburger (inferior good) is consumed than steak (normal good). As income increase, consumption of hamburger decreases as consumption of steak increases.

In the experiment conducted by DeGrandpre et al., smokers who had abstained from smoking for 5-6 hours before each session were allowed to choose between two cigarettes: either their usual brand or another brand that the subjects previously rated as being least preferred on a menu of cigarettes with equivalent nicotine content. Subjects could purchase either their usual brand at the price of $\$ 0.50$ per 2 puffs or the less preferred brand for $\$ 0.10$ per 2 puffs. These prices remained constant throughout the experiment. Income (the amount of money they were given at the beginning of each session) was varied across session and unspent money was forfeited at the end of the session.

Figure 11 shows that as income increased, consumption of the preferred brand of cigarettes (filled squares) increased and consumption of the non-preferred brand (open circles) decreased in all seven subjects. Increased consumption of the usual brand and decreased consumption of the less preferred brand of cigarettes as incomes were increased, empirically demonstrate normal and inferior goods, respectively. Further these data demonstrate that income changes can produce preference reversals even when reinforcer type, magnitude, and price remain unchanged. Such a demonstration suggests that income can be a powerful variable influencing drug choice.

Insert Figure 11 About Here

These data suggest that two forms of differentially priced nicotine may be used in lieu of one another depending upon income. This result has some interesting implications for nicotine replacement products that deliver nicotine but do not produce the negative health outcomes associated with inhaling the smoke of burnt plant product. These nicotine replacement products provide only a small part of the package associated with tobacco 
smoke (e.g., nicotine) and do not provide others (e.g., taste). Thus, these products may substitute for one another, but the nicotine replacement ptoducts may function as inferior goods relative to tobacco smoking. As such, health policies to produce harm reduction could consider two coordinated policies. First, the safer nicotine replacement products should be widely available (e.g., convenience stores) with prices lower than tobacco cigarettes. Second, tobacco taxes should be raised substantially so that smokers who to continue smoking at the same rate would experience a reduction in real income. As such, lower income individuals in particular would be expected to switch to the inferior but safer product. Given that lower SES groups have been relatively insensitive to prior public policy and educational efforts designed to reduce cigarette smoking, data from the present experiment suggest a novel approach in reaching a particularly at-risk segment of cigarette smokers. These speculations may be worthwhile exploring in future behavioral economic studies.

\section{Qverall Conclusions}

In this paper, we attempted to answer three questions relevant in considering the relationship between the economics and behavioral economics of smoking. We answered in the affirmative the question concerning the applicability of economic principles and concepts to the smoking behavior of individuals. Our data suggest that economic principles and concepts are relevant and do pertain to individual smokers. Moreover, the demand curve obtained in these experiments appear to have wide generality.

To the question "Does the behavioral economic data reflect the empirical results in econometric studies of cigarette smoking?" our answer is not a simple yes or no. The analysis of demand reveals several points of comparability when our sample is compared to overall US consumption. However, when our sample is broken into subgroups, the data are consistent with the economic literature for some demographic analyses, but not for others. Whether the inconsistencies are due to restricted sample size, an unrepresentative sample, or some other reason is not yet clear. Nonetheless, these results suggest that the 
use of the behavioral economic data to model the behavior of particular subgroups of cigarette consumers is very limited at this time.

The third question regarding the use of the behavioral economic laboratory to examine issues of policy, the answer is a qualified yes. These studies can inform policy makers because our laboratory model demonstrates economic principles, examines the potential consequences of using a range of cigarette prices beyond what is typical in the natural economy, and our results tend to be consistent with overall US demand. However, given our answer to the second question that we posed to ourselves, the applicability of these results to any demographic subgroup must be made cautiously. Nonetheless the type of experiments reviewed here may be useful in modeling the outcomes of health policy and therefore could inform policy makers.

In closing, the behavioral economics of smoking is an evolving field. The current evaluation shows that the economics and the behavioral economics of smoking share a great deal. They may usefully inform each other because economic principles are germane for understanding the smoking behavior of individuals and groups. Together they may better describe the effects of variables which importantly affect cigarette smoking and point to new directions for improving public health. 


\section{References}

Allison, J. (1979). Demand economics and experimental psychology. Behavioral Science, 24, 403-415.

Andrews, R.L. \& Franke, G.R. (1991). The determinants of cigarette consumption: a meta-analysis. Journal of Public Policy Marketing, 81-100.

Atkinson, S. B., Gomulka, J., \& Stern, N. (1984). Household Expenditure On Tobacco 1970-1980: Evidence from the Family Expenditure Survey. London: London School of Economics.

Bickel, W. K., DeGrandpre, R. J., Higgins, S. T., \& Hughes, J. R. (1990). Behavioral economics of drug self-administration. I. Functional equivalence of response requirement and drug dose. Life Science, 47, 1501-1510.

Bickel, W.K., DeGrandpre, R.J., Hughes, J.R., \& Higgins, S.T. (1991). Behavioral economics of drug self-administration. II. A unit-price analysis of cigarette smoking. Journal of Experimental Analysis of Behavior, 55, 145-154.

Bickel, W. K., DeGrandpre, R. J., Higgins, S. T., Hughes, J. R., \& Badger, G. J. (1995). Effects of simulated employment and recreation on cigarette smoking: A behavioral economic analysis. Experimental and Clinical Psychopharmacology 3, 467476.

Bickel, W. K., Hughes, J. R., DeGrandpre, R. J., Higgins, S. T., \& Rizzuto, P. (1992). Behavioral economics of drug self-administration. IV. The effects of response requirement on consumption of and interaction between concurrently available coffee and cigarettes. Psychopharmacology, 107, 211-216.

Carroll, M. E., Lac, S. T., \& Nygaard, S. L. (1989). A concurrently available nondrug reinforcer prevents the acquisition or decreases the maintenance of cocainereinforced behavior. Psychopharmacology, 97, 23-29. 
Chaloupka, F. J. (1990). Men, women, and addiction; The case of cigarette smoking. Unpublished doctoral dissertation, City University of New York graduate school.

Chaloupka, F. J. (1991). Rational addictive behavior and cigarette smoking. Journal of Political Economy. 99, 722-742.

Chaloupka, F. J., \& Wechsler, H. (1991). Price, tobacco control policies and smoking among young adults. Mimeo, University of Illinois at Chicago.

Craig, T. J., \& Van Natta, P. A. (1977). The association of smoking and drinking habits in a community sample. Journal of Studies on Alcohol. 38, 1434-1439.

DeGrandpre, R. J., \& Bickel, W. K. (1995). Human drug self-administration in a medium of exchange. Experimental and Clinical Psychopharmacology, 3, 349-357.

DeGrandpre, R. J., Bickel, W. K., Hughes, J. R., \& Higgins, S. T. (1992). Behavioral economics of drug self-administration. Psychopharmacology, 108, 1-10.

DeGrandpre, R. J., Bickel, W. K., Rizvi, S. A. T., \& Hughes, J. R. (1993). Effects of income on drug choice in humans. Journal of the Experimental Analysis of Behavior. 59, 483-500.

Escobedo, L. G., \& Peddicord, J. P. (1996). Smoking prevalence in US birth cohorts: The influence of gender and education. American Journal of Public Health, 86 , 231-236.

Fagerstrom, K. O., \& Bates, S. (1981). Compensation and effective smoking by different nicotine dependent smokers. Addictive Behaviors, 6, 331-336.

Fagerstrom, K.O. \& Schneider, N.G. (1989). Measuring nicotine dependence: A review of the Fagerstrom tolerance questionnaire. Journal of Behavioral Medicine, 12, 159-182.

Findley, J.D. (1966). Programmed environments for the experimental analysis of human behavior. In W.K. Honig (Ed.). Operant Behavior: Areas of Research and Application (pp. 827-848). Englewood Cliffs, NJ: Prentice-Hall, Inc. 
Fry, V., \& Pashardes, P. (1988). Changing Patterns of Smoking: Are There Economic Causes? London: Institute of Fiscal Studies.

Giovino, G. A., Schooley, M. W., Zhu, B. P., Chismon, J. H., Tomar, S. L., Peddicord, J. P., Merritt, R. K., Husten, C. G., \& Eriksen, M. P. (1994). Surveillance for selected tobacco-use behaviors--United States, 1900-1994. Morbidity and Mortality Weekly Report. 43, 1-43.

Green, L., \& Rachlin, L. (1975). Economic and biological influences on a pigeon's key peck. Journal of the Experimental Analysis of Behavior. 23, 55-62.

Griffiths, R. R., Bigelow, G., E., Henningfield, J. E. (1980). Similarities in animal and human drug-taking behavior. In N. K. Mello (Ed.), Advances in Substance Abuse (Vol. 1, pp 1-90). Greenwich, CT: JAI Press.

Griffiths, R.R., Henningfield, J.E., \& Bigelow, G.E. (1982). Human cigarette smoking: Manipulation of number of puffs per bout, interbout interval and nicotine dose. Journal of Pharmacology and Experimental Therapeutics, 220, 256-265.

Hay, D. R., \& Foster, F. H. (1984). Intercensal trends in cigarette smoking in New Zealand 2: Social and occupational factors. The New Zealand Medical Journal, 97, 395-398.

Hughes, J. R., \& Hatsukami, D. (1986). Signs and symptoms of tobacco withdrawal. Archives of General Psychiatry, 43, 289-294.

Hursh, S. R. (1980). Economic concepts for the analysis of behavior. Journal of the Experimental Analysis of Behavior, 34, 219-238.

Hursh, S. R. (1991). Behavioral economics of drug self-administration and drug abuse policy. Joumal of the Experimental Analysis of Behavior. 56, 377-393.

Hursh, S.R. \& Bauman, R.A. (1987). The behavior analysis of demand. In L. Green \& J.H. Kagel (Eds.). Advances in behavioral economics. Vol. 1 (pp. 117-165). Norwood, NJ: Ablex. 
Hursh, S. R., Raslear, T. G., Bauman, R., \& Black, H. (1989). The quantitative analysis of economic behavior with laboratory animals. 'In K. G. Grunet \& F. Olander (Eds.), Understanding Economic Behaviour (pp. 393-407). Boston, MA: Kluwer Academic.

Lea, S. E. G. (1978). Psychology and economics of demand. Psychological Bulletin. 85, 441-466.

Lewit, E.M. (1989). U.S. tobacco taxes: Behavioral effects and policy implications. British Joumal of Addictions, 84, 1217-1235.

Lewit, E. M., \& Coate, D. (1982). The potential for using excise taxes to reduce smoking. Journal of Health and Economics, 1, 121-145.

Lewit, E. M., Coate, D., \& Grossman, M. (1981). The effects of government regulation on teenage smoking. Journal of Law and Economics. 24, 545-569.

Mullahy, J. (1985). Cigarette smoking; Habits, health concerns, and heterogenous unobservables in a microeconomic analysis of consumer demand. Unpublished doctoral dissertation, University of Virginia.

Neisser, U., Boodoo, G., Bouchard, T. J., Boykin, A. W., Brody, N., et al. (1996). Intelligence: Knowns and unknowns. American Psychologist. 51, 77-101.

Pearce, D.W. (1986). The MIT Dictionary of Modern Economics. Cambridge, MA: The MIT Press.

Pierce, J. P., Fiore, M. C., Novotny, T. E., Hatziandreu, E. J., \& Davis, R. M. (1989). Trends in cigarette smoking in the United States: Educational differences are increasing. Journal of the American Medical Association. 261, 56-60.

Pinto, R. P., Abrams, D. B., Monti, P. M., \& Jacobus, S. I. (1987). Nicotine dependence and likelihood of quitting smoking. Addictive Behaviors 12, 371-374.

Samuelson, P.A. \& Nordhaus, W.D. (1985). Economics. New York: McGrawHill. 
Sechrest, L.B., \& Bootzin, R.R. (1996). Psychology and inferences about public policy. Psychology Public Policy and Law, $2,377-392$.

Skinner, B. F. (1953). Science and Human Behavior (p. 400). New York: Free Press.

Townsend, J. (1987). Cigarette tax, economic welfare and social class patterns of smoking. Applied Economics, 19, 335-365.

Townsend, J., Roderick, P., \& Cooper, J. (1994). Cigarette smoking by socioeconomic group, sex and age: Effects of price, income and health publicity. British Medical Journal, 309, 923-927.

Zacny, J. P. (1990). Behavioral aspects of alcohol-tobacco interactions. Recent Developments in Alcoholism, 8, 205-219.

Zacny, J.P., Stitzer, M.L., Brown, F.J., Yingling, J.E., \& Griffiths, R.R. (1987). Human cigarette smoking: effects of puff and inhalation parameters on smoke exposure. Journal of Pharmacology and Experimental Therapeutics, 240(2), 554-564. 
Author Notes

Warren K. Bickel, Departments of Psychiatry and Psychology, Gregory J.

Madden, Department of Psychiatry, University of Vermont. The research was supported by National Institute on Drug Abuse grants DA06526 and T32 DA07242.

We wish to thank Gary Badger who assisted in data analysis, Rob McIntyre from the Vermont Department of Health who provided data concerning demographics of US smokers, and Brandi Smith and Lisa Marsch, who provided useful comments on an earlier version of this chapter.

Correspondence concerning this chapter should be addressed to Warren K. Bickel, Human Behavioral Pharmacology Laboratory, Department of Psychiatry, University of Vermont, 38 Fletcher Place, Burlington, VT 05301-1419. Electronic mail may be sent via the Internet to warren.bickel@uvm.edu. 
Table 1. Individual subject point-price and arc- elasticities at and across fixed ratio (FR) $100 \& 200$ schedules. Data from Bickel et al. (1995).

Point-Price Elasticities

\begin{tabular}{cccc} 
Subject & Arc Elasticity & FR 100 & FR 200 \\
\hline BM & -0.43 & -0.27 & -0.34 \\
MN & -0.50 & -0.03 & -0.17 \\
MQ & -0.30 & -0.18 & -0.40 \\
RA & -0.76 & -0.38 & -0.43 \\
BRM & -0.31 & -0.14 & -0.26 \\
\hline
\end{tabular}


Table 2. Unit prices and point-price elasticities from Bickel et al. (1995). Average point-price elasticities are shown for individual subjects.

\begin{tabular}{|c|c|c|}
\hline Subject & $\begin{array}{c}\text { Unit } \\
\text { Price }\end{array}$ & $\begin{array}{c}\text { Point-price } \\
\text { Elasticity }\end{array}$ \\
\hline \multirow[t]{9}{*}{$\mathrm{BM}$} & 12 & -0.21 \\
\hline & 25 & -0.22 \\
\hline & 50 & -0.24 \\
\hline & 100 & -0.27 \\
\hline & 200 & -0.34 \\
\hline & 400 & -0.49 \\
\hline & 800 & -0.78 \\
\hline & 1600 & -1.35 \\
\hline & Average & -0.49 \\
\hline \multirow[t]{9}{*}{$\mathbf{M N}$} & 12 & 0.10 \\
\hline & 25 & 0.08 \\
\hline & 50 & 0.04 \\
\hline & 100 & -0.03 \\
\hline & 200 & -0.17 \\
\hline & 400 & -0.45 \\
\hline & 800 & -1.02 \\
\hline & 1600 & -2.16 \\
\hline & Average & -0.45 \\
\hline \multirow[t]{9}{*}{$\mathbf{M Q}$} & 12 & 0.01 \\
\hline & 25 & -0.02 \\
\hline & 50 & -0.07 \\
\hline & 100 & -0.18 \\
\hline & 200 & -0.40 \\
\hline & 400 & -0.83 \\
\hline & 800 & -1.70 \\
\hline & 1600 & -3.44 \\
\hline & Average & -0.83 \\
\hline \multirow[t]{9}{*}{$\mathbf{R A}$} & 12 & -0.34 \\
\hline & 25 & -0.35 \\
\hline & 50 & -0.36 \\
\hline & 100 & -0.38 \\
\hline & 200 & -0.43 \\
\hline & 400 & -0.52 \\
\hline & 800 & -0.71 \\
\hline & 1600 & -1.09 \\
\hline & Average & -0.52 \\
\hline \multirow[t]{9}{*}{ BRM } & 12 & -0.04 \\
\hline & 25 & -0.05 \\
\hline & 50 & -0.08 \\
\hline & 100 & -0.14 \\
\hline & 200 & -0.26 \\
\hline & 400 & -0.49 \\
\hline & 800 & -0.96 \\
\hline & 1600 & -1.89 \\
\hline & Average & -0.49 \\
\hline
\end{tabular}


Table 3. Point-price elasticities from DeGrandpre \& Bickel (1995). Average point-price elasticities are shown for each subject).

\begin{tabular}{|c|c|c|}
\hline Subject & $\begin{array}{l}\text { Unit } \\
\text { Price }\end{array}$ & $\begin{array}{c}\text { Point-price } \\
\text { Elasticity }\end{array}$ \\
\hline \multirow[t]{6}{*}{ DH } & 400 & -0.44 \\
\hline & 800 & -0.49 \\
\hline & 1600 & -0.60 \\
\hline & 3200 & -0.81 \\
\hline & 4500 & -0.99 \\
\hline & Average & -0.66 \\
\hline \multirow{6}{*}{ JL } & 400 & -0.03 \\
\hline & 800 & -0.16 \\
\hline & 1600 & -0.56 \\
\hline & 3200 & -1.34 \\
\hline & 4500 & -1.98 \\
\hline & Average & -0.80 \\
\hline \multirow[t]{6}{*}{ WH } & 400 & -0.05 \\
\hline & 800 & -0.81 \\
\hline & 1600 & -2.32 \\
\hline & 3200 & -5.35 \\
\hline & 4500 & -7.81 \\
\hline & Average & -3.27 \\
\hline \multirow[t]{6}{*}{ WR } & 400 & -0.73 \\
\hline & 800 & -0.19 \\
\hline & 1600 & -0.89 \\
\hline & 3200 & -3.06 \\
\hline & 4500 & -4.82 \\
\hline & Average & -1.57 \\
\hline
\end{tabular}


Table 4. Point-price elasticites, and average price elasticity from Findley (1966).

\begin{tabular}{cc}
$\begin{array}{c}\text { Unit } \\
\text { Price }\end{array}$ & $\begin{array}{c}\text { Point-price } \\
\text { Elasticity }\end{array}$ \\
\hline 25 & 0.08 \\
50 & 0.01 \\
100 & -0.14 \\
200 & -0.43 \\
300 & -0.72 \\
500 & -1.30 \\
Average & -0.41 \\
\hline
\end{tabular}


Table 5. Point-price elasticities and average price elasticity derived from per capita smoking data presented by Lewit (1989).

\begin{tabular}{cc}
$\begin{array}{c}\text { Price } \\
\text { (cents per pack }\end{array}$ & $\begin{array}{c}\text { Point-price } \\
\text { Elasticity }\end{array}$ \\
\hline 57 & -0.14 \\
61 & -0.16 \\
67 & -0.19 \\
74 & -0.23 \\
89 & -0.32 \\
95 & -0.35 \\
101 & -0.38 \\
108 & -0.43 \\
116 & -0.47 \\
Average & -0.29 \\
\hline
\end{tabular}


Table 6. Demographic characteristics of 74 smokers whose data were included in the present analysis. Values shown are either means (SD) or percent of subjects fitting each category.

\begin{tabular}{ll} 
\% Male & 56.7 \\
Age & $32.0(8.6)$ \\
Cigarettes per day & $25.7(7.9)$ \\
Fagerstrom Tolerance Questionnaire Score & $7.5(1.4)$ \\
\% Caucasian & 94.0 \\
Education (years) & $12.7(2.1)$ \\
\% Employed (full or part-time) & 44.6 \\
Coffee per day (cups) & $2.9(2.9)$ \\
Alcohol Consumption & 25.7 \\
$\%$ Nondrinkers & 27.0 \\
$\%$ 1-2 times/month & 16.2 \\
$\%$ 1 time/week & 24.3 \\
$\%$ 2-3 times/week & 6.8 \\
\%4+ times/week & 50.1 \\
\% Consuming <2 drinks per episode & $4.0(4.2)$ \\
Beck's Depression Inventory score & \\
\hline
\end{tabular}


Table 7. Mean of individual subjects' estimated price elasticity of demand values at eight different unit prices.

\begin{tabular}{ccc}
\hline Unit Price & $\begin{array}{c}\text { Price Elasticity } \\
\text { of Demand }\end{array}$ & $\begin{array}{c}\text { Standard } \\
\text { Error }\end{array}$ \\
\hline & & \\
10 & -0.072 & 0.028 \\
25 & -0.098 & 0.027 \\
50 & -0.141 & 0.027 \\
100 & -0.228 & 0.036 \\
200 & -0.400 & 0.065 \\
400 & -0.746 & 0.134 \\
800 & -1.436 & 0.277 \\
1,600 & -2.816 & 0.564 \\
Mean & -0.742 & \\
\hline
\end{tabular}


Table 8. Demographic variables which were significant in stepwise regression analysis predicting arc elasticity across unit prices 200 and 400 (prediction made for elasticities of log consumption). Parameter coefficients (SE) of each variable in the final equation are shown with percent variance accounted for by individual variables and the full model.

\begin{tabular}{lrr} 
Order & $\begin{array}{c}\text { Parameter } \\
\text { Coefficient }\end{array}$ & $\mathrm{R}^{2}$ \\
\hline Constant & $-0.43(0.40)$ & \\
FTQ Score & $0.08(0.02)$ & 0.05 \\
Education Level $^{\ddagger}$ & $-0.05(0.03)$ & 0.05 \\
Overall & & 0.10 \\
\hline
\end{tabular}

$\$ \mathrm{p} \leq .10$ 
Table 9. Demographic variables which were significant in stepwise regression analysis predicting cigarette puff intake per session at unit prices 200 and 400 (prediction made for log consumption). Parameter coefficients (SE) of each variable in the final equation are shown with percent variance accounted for by individual variables and the full model.

\begin{tabular}{|c|c|c|c|}
\hline Unit Price & Order & $\begin{array}{l}\text { Parameter } \\
\text { Coefficient }\end{array}$ & $\mathrm{R}^{2}$ \\
\hline 200 & $\begin{array}{l}\text { Constant } \\
\text { FTQ Score } \\
\text { Education Level }^{*} \\
\text { Gender (male }=1)^{\dagger} \\
\text { Alcohol per Episode }^{\dagger} \\
\text { Employment Status } \\
\text { Overall }^{\ddagger}\end{array}$ & $\begin{array}{r}3.31(0.56) \\
0.15(0.05) \\
-0.10(0.03) \\
0.39(0.14) \\
-0.35(0.14) \\
-0.24(0.14)\end{array}$ & $\begin{array}{l}0.09 \\
0.11 \\
0.05 \\
0.06 \\
0.03 \\
0.34\end{array}$ \\
\hline 400 & $\begin{array}{l}\text { Constant } \\
\text { FTQ Score } \\
\text { Education Level } \\
\text { Alcohol per Episode } \\
\text { Gender (male }=1)^{\ddagger} \\
\text { Overall }\end{array}$ & $\begin{array}{r}3.13(0.73) \\
0.19(0.06) \\
-0.14(0.04) \\
-0.38(0.19) \\
0.35(0.18)\end{array}$ & $\begin{array}{l}0.11 \\
0.12 \\
0.03 \\
0.04 \\
0.29\end{array}$ \\
\hline
\end{tabular}

\footnotetext{
${ }^{*} \mathrm{p} \leq .01$

$\dagger \mathrm{p} \leq .05$

$\ddagger \mathrm{p} \leq .10$
} 


\section{Figure Captions}

Figure 1. Number of cigarette puffs individual subjects smoked in each 3-hour session at two different response requirements. Data originally reported by Bickel et al. (1995).

Figure 2. Number of cigarette puffs individual subjects smoked in each 3-hour session at a range of unit prices; note the double logarithmic axes. Demand curves were fit to consumption data using Equation 2. Data originally reported by Bickel et al. (1995).

Figure 3. Number of cigarette puffs individual subjects smoked in each 3-hour session at a range of unit prices; note the double-logarithmic axes. Demand curves were fit to consumption data using Equation 2. Data originally reported by DeGrandpre et al. (1995).

Figure 4. Number of cigarette puffs smoked per 24-hour period across a range of response requirements. Consumption data were estimated from Findley's (1966) Figure 7. The demand curve was fit using Equation 2. Data on both axes were converted to logarithms to show proportional change in consumption as a function of price increases (i.e., the point slope of the demand curve provides a measure of elasticity).

Figure 5. Per capita cigarette consumption as a function of the annual mean price per pack of cigarettes. Price and consumption data were estimated from Lewit's (1989) Figures 2 and 5, respectively. The demand curve was fit to these data using Equation 2. Data on both axes were converted to logarithms to show elasticity changes as a function of price.

Figure 6. Amount of drug consumed per drug self-administration session across a range of unit prices; note the double-logarithmic axes. The unit price of six different drugs or drug combinations was manipulated either by changing the dose of drug delivered at each selfadministration or by changing the response requirement necessary to produce one selfadministration. Data are reprinted from Bickel et al. (1990).

Figure 7. Mean predicted consumption across a range of unit prices typically examined in the behavioral economics laboratory (see text for details on estimating individual subjects' predicted consumption at each unit price). The demand curve was fit to these predicted consumption values using Equation 2. 
Figure 8. Predicted arc elasticity values across a change in unit price from 200 to 400 as a function of three different levels of the two demographic characteristics of our subjects that significantly predicted arc elasticity changes in a stepwise regression analysis: Fagerstrom Tolerance Questionnaire (FTQ) scores and years of completed formalized education.

Figure 9. Predicted number of cigarette puffs consumed per 3-hour session at unit prices 200 and 400 . Individual graphs show effects on smoking of demographics that significantly predicted consumption in stepwise regression. Effects of employment status on predicted consumption are not shown at unit price 400 because this demographic was not significant at this unit price.

Figure 10. Demographic effects on predicted number of cigarette puffs consumed per 3hour session at the range of unit prices examined in Figure 7. T-tests revealed significant consumption differences $(*: p \leq .05 ;+: \mathrm{p} \leq .10)$ across the two levels of each demographic at some unit prices.

Figure 11. Effects of income manipulations on the number of subjects' own brand and another, less preferred, brand of cigarettes consumed per 3-hour session. 


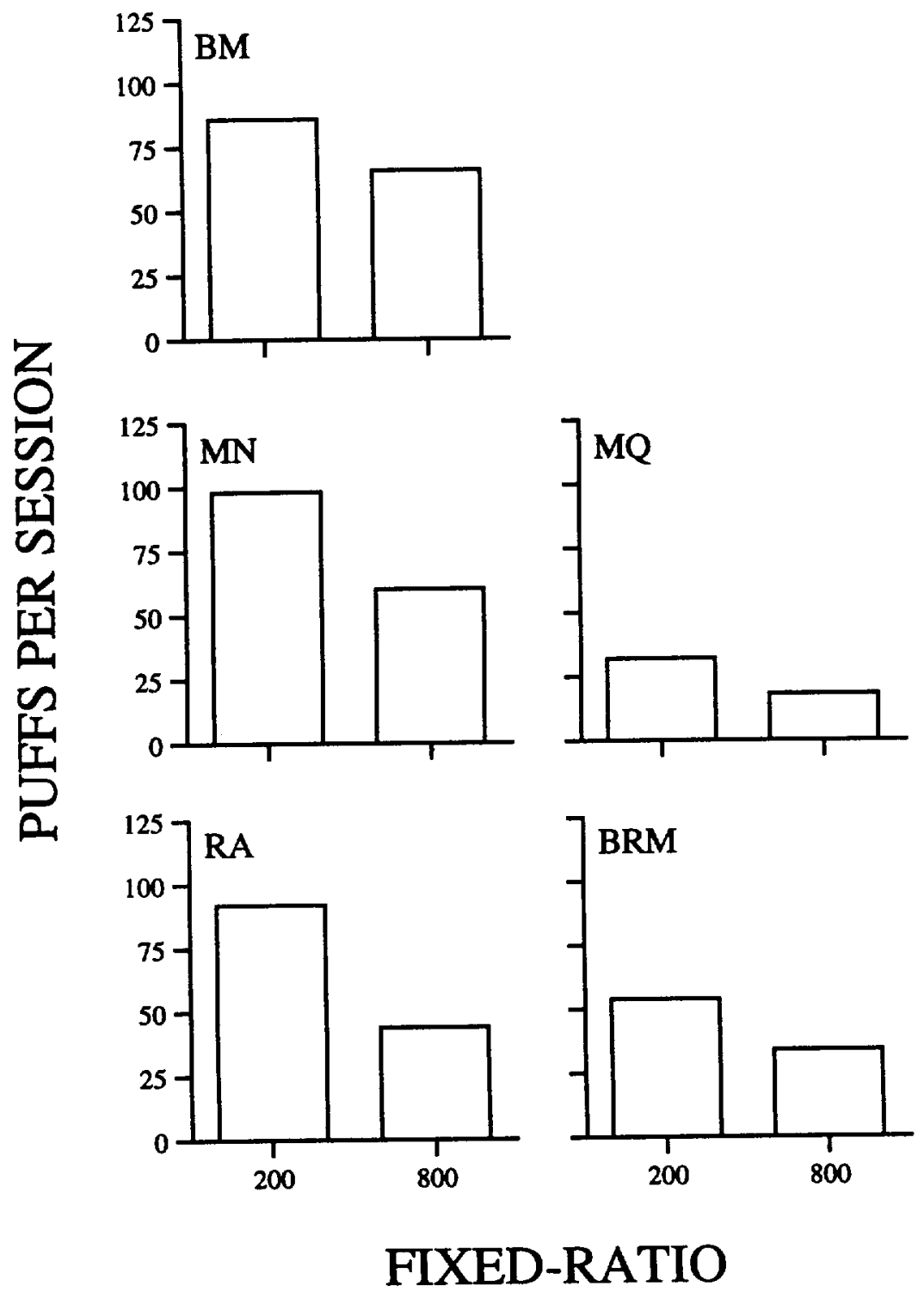




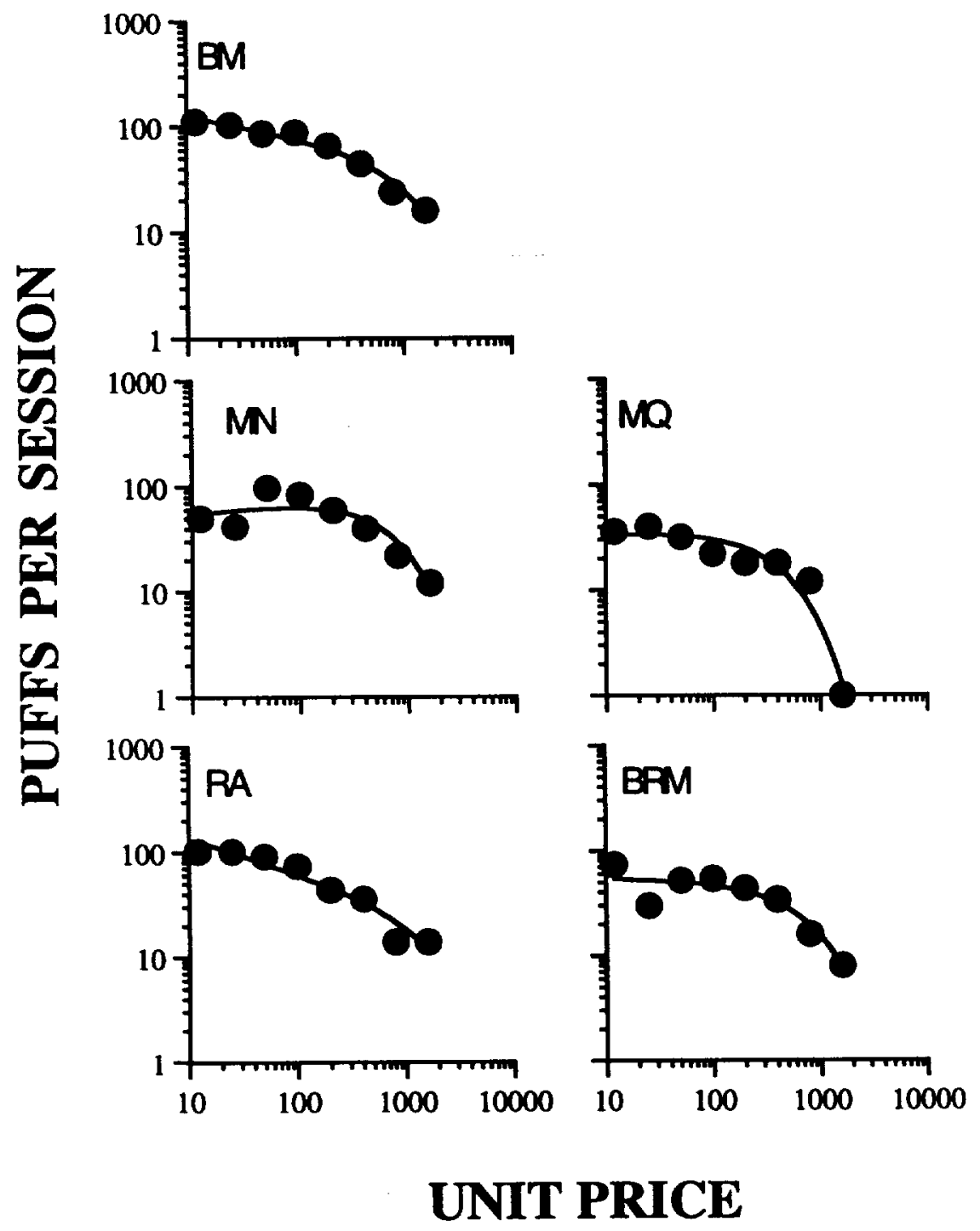




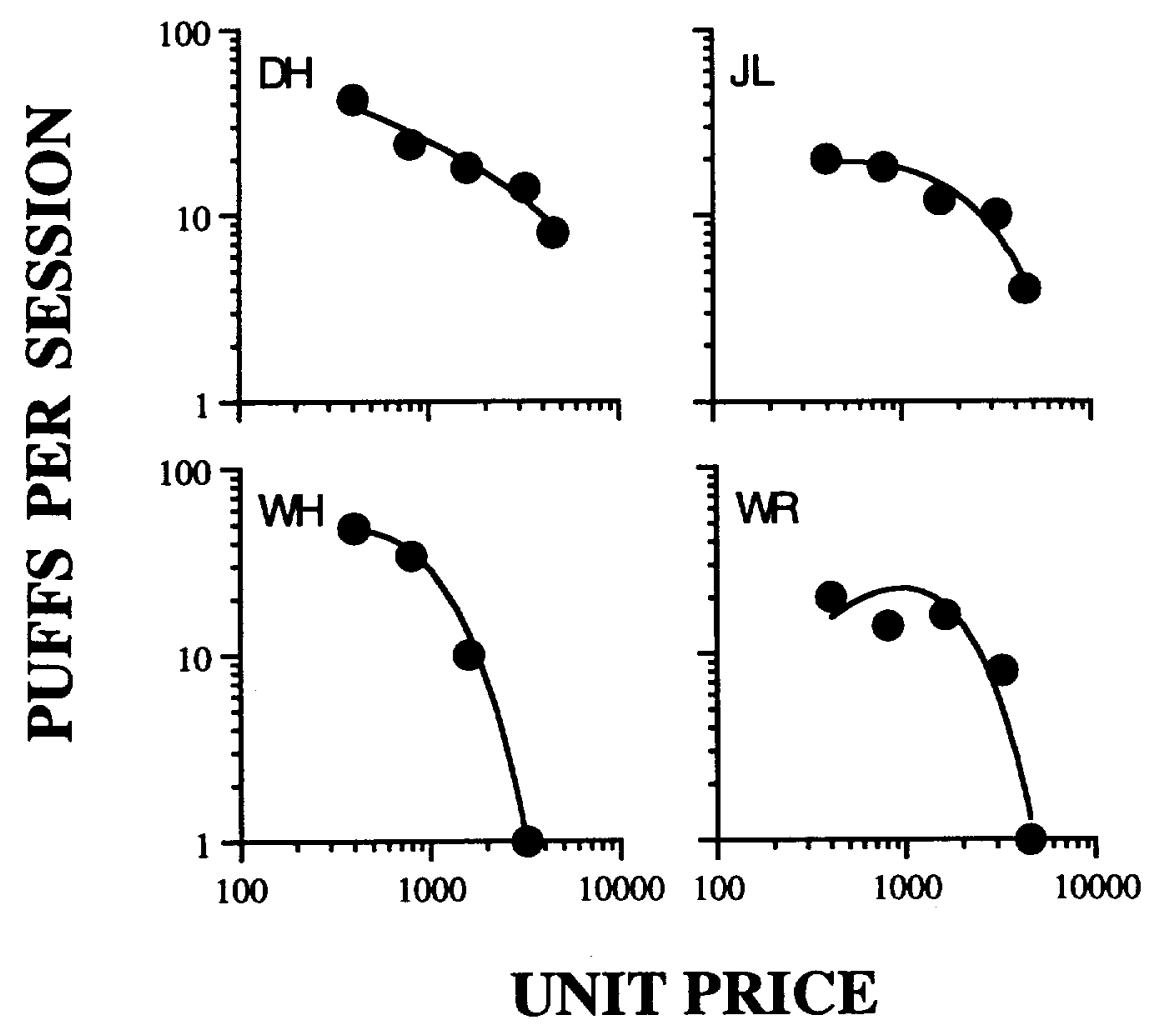




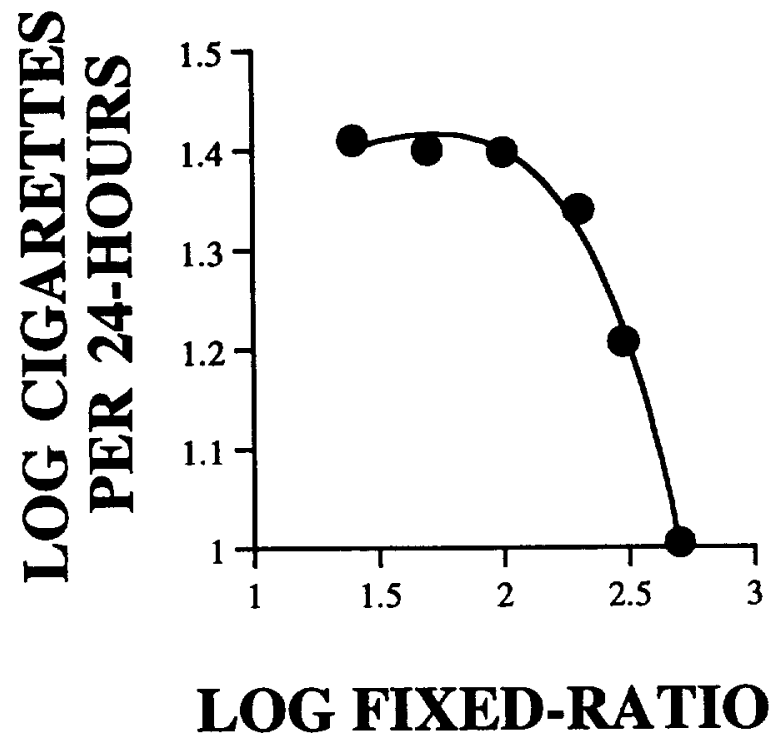




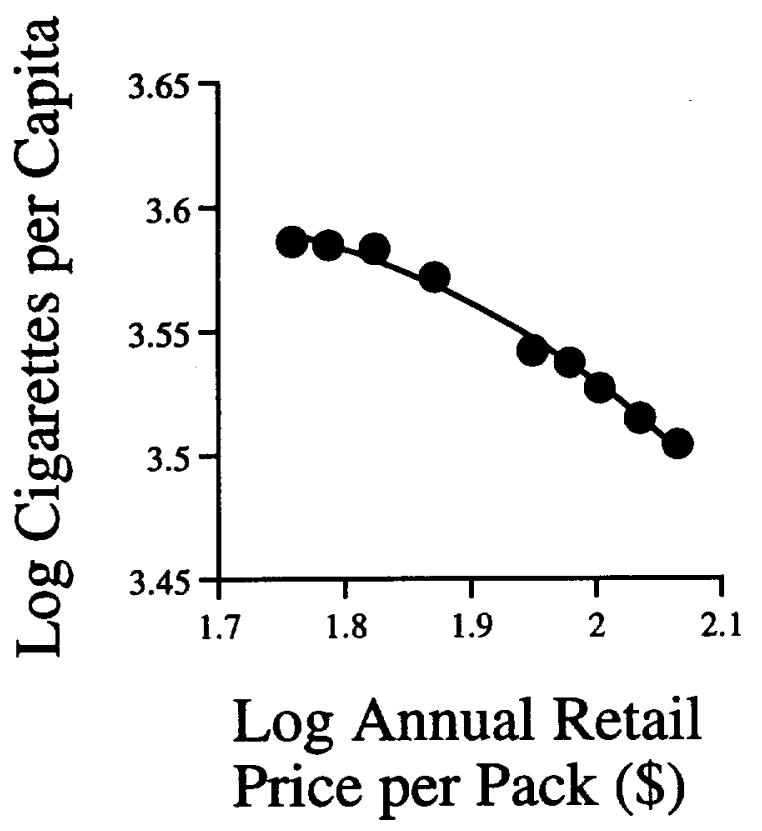





I MAIT DRICE 


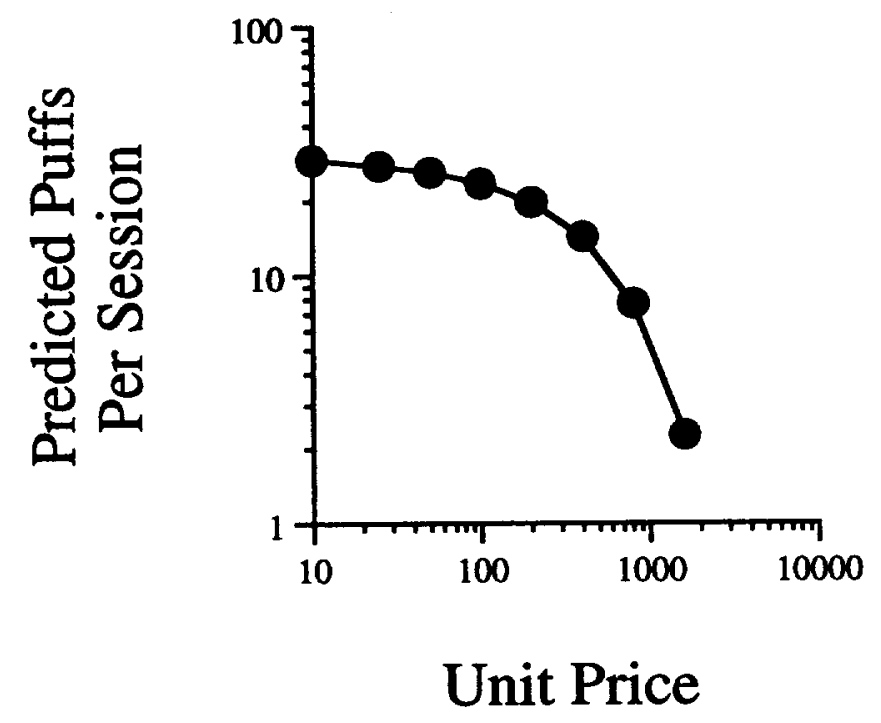




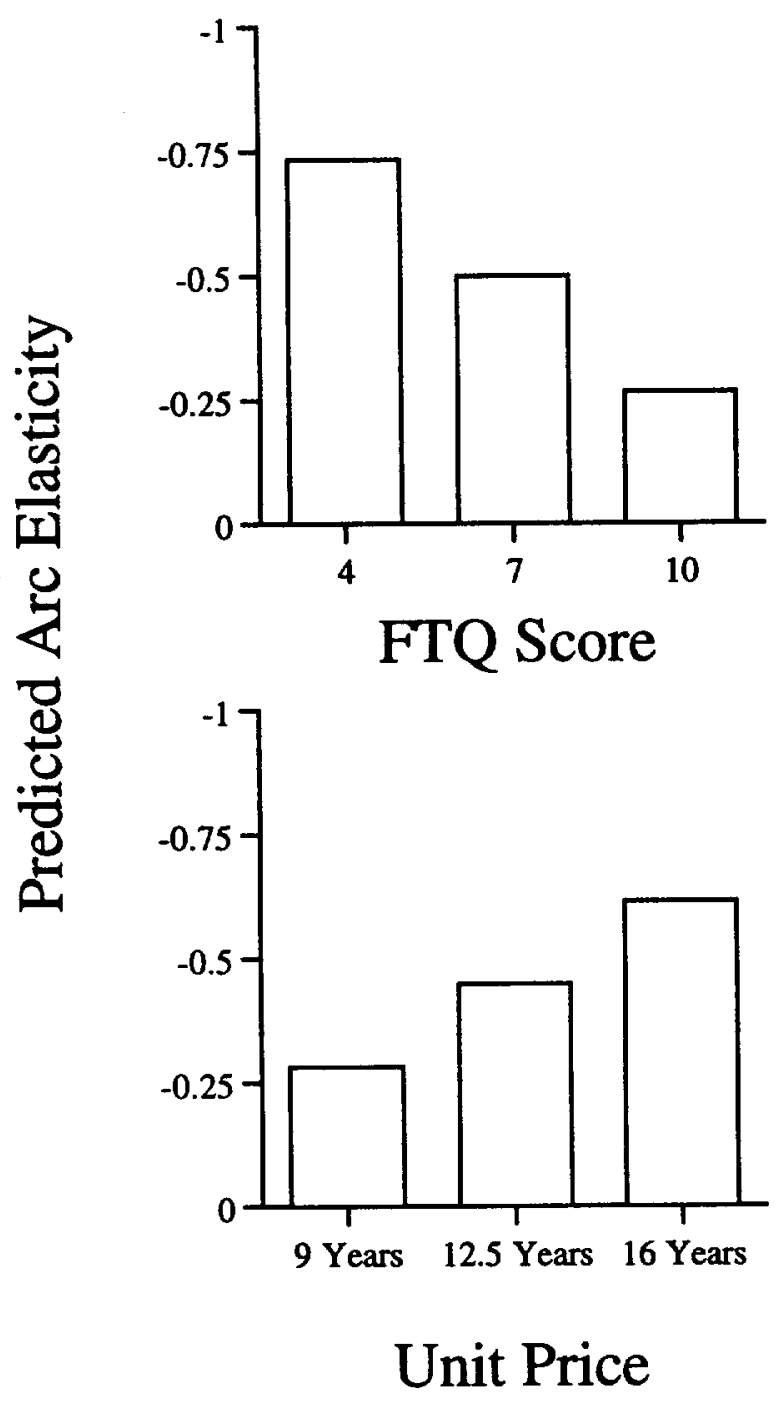



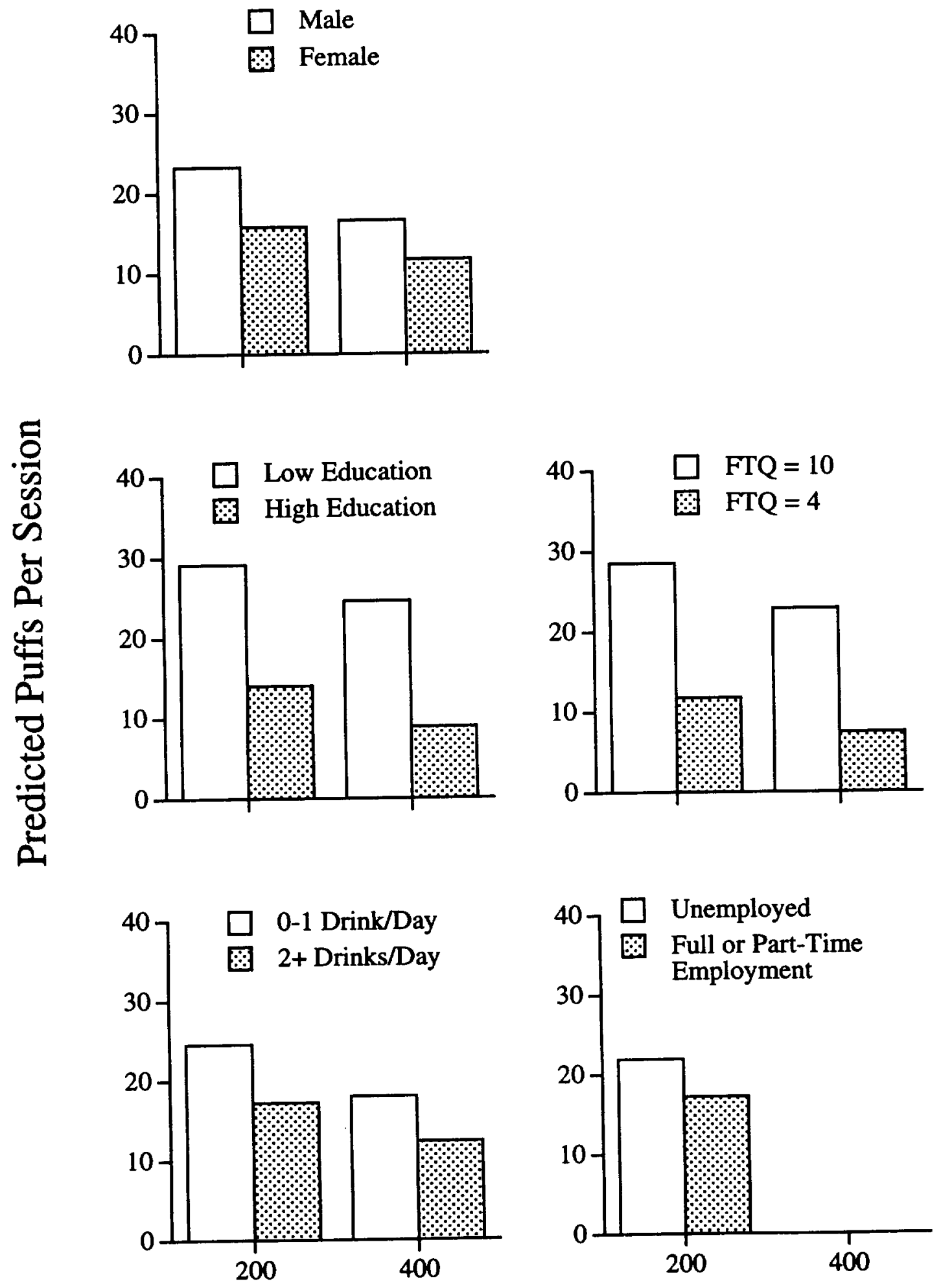

Unit Price 


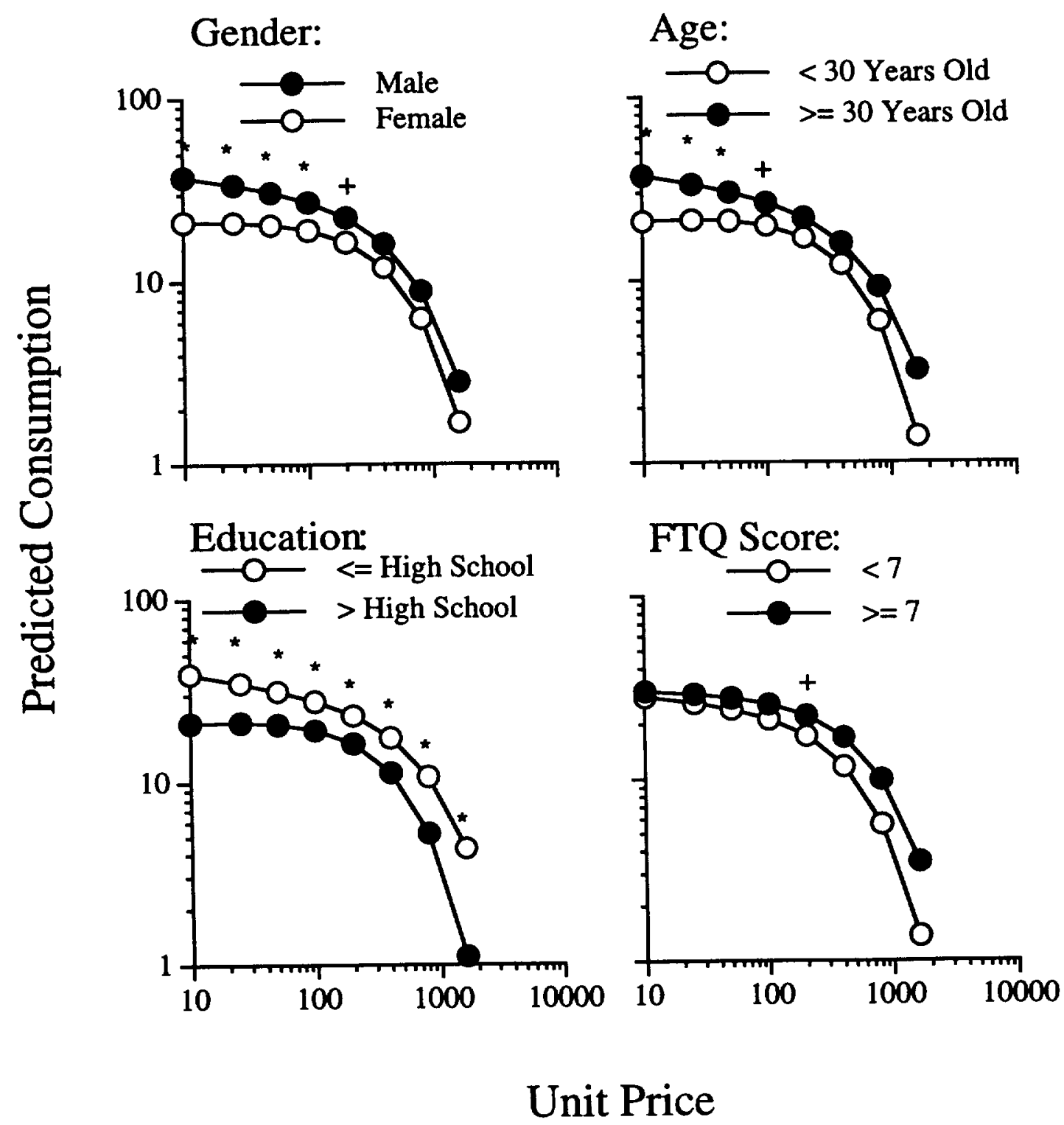




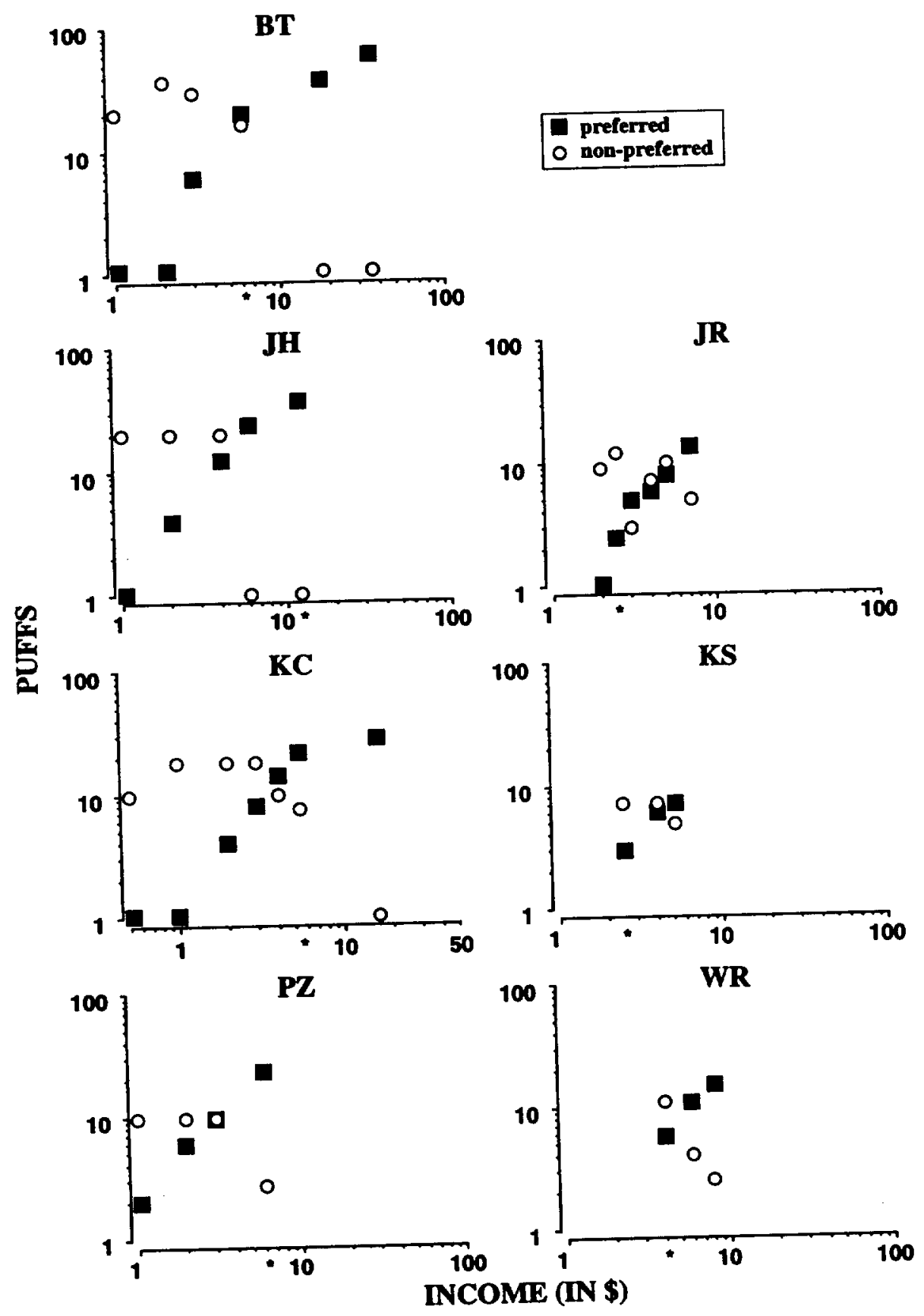

